\title{
MAŁŻEŃSTWO W NAUCZANIU I PRAWODAWSTWIE NESTORIAN
}

1. Z $\mathrm{r}$ d $z$ a. Koścíb nestorlański az do IX w. posługiwaz sie witurgil 1 piśmiennictwie teologicznym jezykiem syryjskim, a dopiero późntej pojawiły się dzieła w Jęyku arabskim. Językiem liturgil pozostaz nadal jezyk eyryjoki, który w XI stuleciu przezywal swój złoty wiek.

Głównym źródłem do poznania prawodawstwa nestorian sa dokumenty synodów tzw. Synodica, obejmujace około 80 poszczególnych tytuzón 12000 rękopisóm 1 . Oto wykaz najwazniejszych zbiorów, do których naleza m.1n. akta: Synodu Izaaka $/ 410 \mathrm{r} . /$, Synodu Jahballaha $/ 420 \mathrm{r} \cdot /$,

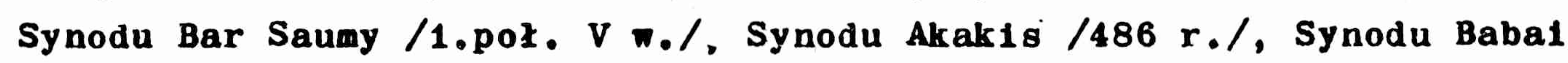
$/ 497 \mathrm{r} . /$, Synodu Mār Ab̄ā $/ 544$ r./, Synodu Józefa /554 r./, Synodu Ezechiela $/ 576 \mathrm{r} . /$, Synodu İ̌o' jahba $/ 585 \mathrm{r} . /$, Synodu Sabrrī̌o $/ 596$ r./, Synodu Grzegorza I /605 r./ 1 Synodu Hnanišl II /775 r./ oraz Ksiega praw Hnanţ̌o, Księga praw Tymoteusza I /728-823 r./, Księga praw

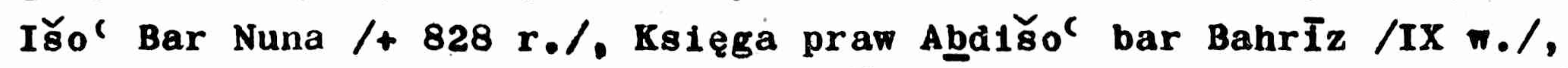
Księga praw Symeona 1 Księga praw Išo' bokta /VIII/IX w./.

Drugim waźnym gatunkiem źródel są zbiory praw nestoriańskiego Kościoła, tzw. kompendia, spośód których najbardziej znane sa Ellasza al-Gauhariego, metropolity Damaszku 1 Eliasza, metropolity jerozolimskiego pisane po arabsku /X w./. Z poczatku XI w. pochodzI dzieło Ibn aṭ-Taijlba", "Prawo chrześcijan"/FIqh an-nasrānIja/, składające sie z dwu ozę́fil: pierwszej zawierającej materlaz źródłowy

1 Por. W.Selb, Orientalisches Kirchenreoht, Bd.1: Die Geschichte des Kirchenrechts der Nestorianer, Wien 1981, $57 \mathrm{n}$.

2 W.Hoenerbach, 0.Sp1es, Ibn at-Taij1b, F1qh an-Naşrāñ̄ja, "Das Recht der Christenheit", 2 Téile, Louvain 1956-1957. CSCo 161/2, $167 / 8 /=$ Scriptores arabicl $16-19 /$. 
będacy wyclagiem z synodów $i$ drugiej stanowiacej przemazającej części przekład dzieła Gabriela z Basry. W Jezyku syryjokim zachowały sie ponadto kompendia Gabriela z Basry / $893 /$ wydane przez H.Kaurholda ${ }^{3}$ oraz późniejsze Abdīšocbar Brīkāa $/+1318 /$, składające się z dwu częśc1: "Collectio canonum synodicorum" 1 "Ordo Iudic1orum ecclesiasticorum".

Wybitnym popularyzatorem nestorlańskiego prawa by niemiecki syrolog E.Sachau, który wspólnie z K.G.Brunsem wydał "Syrisch-Kømisches Rechtsbuch" ${ }^{4}$, a następnie sam fundamentalne trzytomowe dzieło "Syrische Rechtsbucher" 5 .

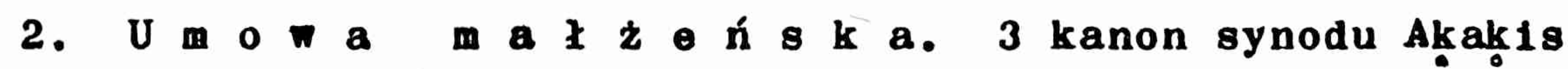
/486 r./ po raz pierwszy sformułował reguły dotyczace małzeństwa chrześcijańskiego. Naturę małzeŕstwa wyjaśniali ponadto: patriarcha Mār Ab̄ā $w$ komentarzu do Kpł $181 \mathrm{Kpl} 20,10-21^{6} 1$ Išol jahb I. Mazzeństwo jako instytucja chrzescijańska zostało obronione przed niektorymi niewlaścinymi formami ascetycznymi. Małzeństwo 1 rodzenie nie były złem/kan. 3 synodu Akakjis/ ale zwiazkiem męzczyzny z kobietą. Kto poją zonę, wypełnił nakaz Apostoła. Celem małzeństwa było rodzenie dzieci, a zapobieganie temu było uchybieniem przeciw jego 1stocie ${ }^{7}$. Dochodziło ono do skutku, podobnie jak u zydow 1 sąsiednich narodów or lentalnych dwuetapowo: przez umowe małzeńska mk̄irūtā lub mkūryā tłumaczone jako "kupno" 1 przez przeprowadzenie

3 H.Kaufhold, Die Rechtssammlung des Gabriel von Basra und ihr Verhaltnis zu den anderen juristischen Sammelwerkèn der Nestorianer, Berlin 1976.

4 Leipzig 1890.

5 E.Sachau, Syrische Hechtsbltcher, Bd.1: Leges Constantin1, Theodosi1, Leon1s, Berlin 1907; Syrische Rechtsblicher, Bd.2, Berlin 1908 /zawierało Sędziowskie wyroki patriarchy HnānIsō, Ksiege praw Patriarchy Tymoteusza, Księge praw Patriarchy Išo'bar Nuna/; Syrische Rechtsbtcher, Bd.3, Berlin 1914 /obejmowało Corpus 1 uris perskiego arcybiskupa Išo'bokta, Prawo zlemskie 1 kanony perskiego arcybiskupa Symeona, Prawo małzeńskie Mār Ab̄ä/.

6 0.Braun, Das Buch der Synhados oder Synodicon Orientale, StuttgartW1 on 1900 /Reprint Amsterdam 1975/, $127 \mathrm{n}$.

7 W.Selb,dz.cyt., 149. 
do domu. Często umowa małzeńska była sporządzana juz wczéńej przez rodzlców dla swolch dzleci, a przeprowadzente do domu następomało pó́niej, aby małzeństwo mogło byé dopełnione ${ }^{8}$.

Chrześcijański fundament Jedności małżéstwa nestoriariskiego opierał się zasadniczo na tekście św.Mateusza: "Co Bóg złączył, człowiek niech nie rozdziela" /19,6/; który Išol bokt wyraźnie cytu$\mathrm{Je}^{9}$. W czasach $1 \mathrm{slamu}$ nastąiła dalsza konkretyzacja podstawowych przepisów prawa małżésklego, dokonana głównte przez trzech pisarzy działajacych na przełomie VIII 1 IX w. - Išol bokta, Tymoteusza I 1. Išo' bar Nuna. Hówniez kościelne zakazy małzeństwa sformułowane na podstawie komentarza Mār Ab̄ā do Ksiegi Kapłańskiej/18,3-5; 20, 10-21; 1 Kor $7,14 /$ były dalej rozwijane ${ }^{10}$.

I šo' bokt przez zaręczyny rozumiał układ narzeczonych /tenæal d-māknūre/, na dowód którego mężczyzna przekazywał narzeczonej pieróclonek. Winny się one odbywać wobec kapłana 1 innych duchownych, którzy przekazywali błogosławieństwo: miały one charakter kupna ${ }^{11}$. Udział duchownych nie był zadnym wymsłem Išó bokta, bo juz przed n1m w V w. Narses pisał: - "Bez kapłana kobieta nie zostajo zareczona zęzczyzną 1 bez niego nie odbędzie się uroczystość weselnan ${ }^{12}$. Według 3 kanonu katolikosa Jerzego /676 r./ zareczyny powinny sie dokonywać przez błogosławieństwo kapłana 1 w obecnośc1 krzyża zbawiciela. Nestorianie 13 mięc wcześniej niz Grecy, bo juz od VII w. mieli kośç lne zaręczyny. Išol bokt wyraźnte pisze ze zaręczyny, które nie odbywaja się przed kapłanem, są niewaźne.

Tymoteusz zaś rozrózniał dwa etapy małżeństwa: zaręczyny /mk̄ūi $\mathbf{a} /$ 1 uroczystość meselnt/ălūia/, połączone z przeprowadzeniem do domu. Przez zareczyny rozumiał układ/tenwai/dokonujący sie w obecności kapłana, krzyza i przynajmniej trzech osób świeckich. Autor ten bardziej niż Išo bokt akcentował zaręczyny, które lączą młodych na całe

\footnotetext{
8 Tamze 151.

9 Tamze 210.

10 Tamże 207.

11 H.Kaurhold, dz.cyt., 72.

12 Narsal doctoris syri homiliae et carmina primo edita A.Mingana, Mossoul 1905, t.1, 289.
}

13 H.Kaufhold, dz.cyt., 73. 
zycie.

Išo' bar Nun, następca Tymoteusza również uczył, że zaręczyny muszą się odbywać przed kapłanem 1 świeckimi. Oprócz pierścionka 1 krzyża wymagana jest Hnānā czyli pył ze świętych miejsc zmieszany z wodą lúb oliwa. Jeżeli później partner nie poślubi swej narzeczonej w ciagu czterech lat, jest ona wolna. Pewien anonimowy autor "Expositio officiorum" /IX w./ rozróżniał zaręczny i święto weselne.

Wreszcie Ibn at-Taijib ${ }^{14}$ wymienial nie tylko zaręczyny, lecz mówił także o kościelnej ceremonii ślubnej, która znana była z kościoła greckiego 1 innych kościołów orientalnych w postaci koronowania narzeczonych. Zaręczyny mogły się również odbywać między wolnymi a niewolnikami. Ibn at:-Ta1jib ${ }^{15}$ cytując Išóbokta przytacza wypadek, kiedy niewolnica przed zaręczynami z wolnym otrzymała wolność. Ze względu na to, że zaręczyny u nestorian, podobnie jak u innych ludów orientalnych, posiadały charakter kupna, ustalono, że cena bogatej żony wynosiła 400 dirhamów, a pochodzącej z ubogiej rodziny wahała się od 100 do 300 dirhamów ${ }^{16}$. Autor ten razen $z$ Abdišo'podkreślał ponadto, że układ zaręczynowy dla swojej córki mógł zawrzeć ojciec; jeżeli zaś nie żyı, mógł to zrobić ktoś zajmujący jego miejsce. Rowziazzanie zaręczyn zdaniem Ǐso' bokta następowało po 10 latach; jeżeli zaś nie były one zawarte w formie kanonicznej, mogły być rozwiłzane waźdym czasie.

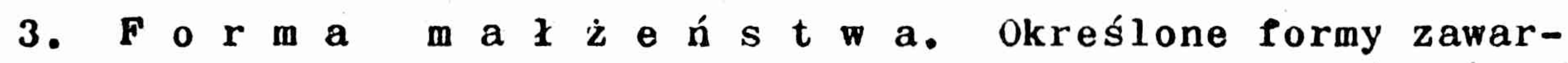
cia małżéstwa rozwinęly się dopiero w późniejszym okresie prawodawstwa nestoriańskiego ${ }^{17}$. Są one wprawdzie akcentowane przez wszystkıch prawników, ale u róźnych autorów 1 w różnym czasie nie sá jednak owe.

We wspólnotach nestoriańskich na terenie Persji na początku IX w., jak opisuje Ǐ̌ol bokt, umowie małżeńskiej towarzyszyło przekazanie obrączek, kapłańskie błogosławieństwo 1 zeznanie świeckich chrześcijan. Gdyby zaś kapłan nie był osizgalny, wystarczyło błoz̧o-

14 Tamże 77.

15 Tamże 81.

16 Tamże 82.

17 W.Selb, dz.cyt., 152. 
slawieństwo śwleckich. Sam jednak układ mógl zaistnieó, nawet gdyby ani duchowny ant świeccy nie wogli go pobłogoskawić. Tymoteusz 1 Išoc bar Nun uważall za wystarczajace do umowy małzeńskiej obecność kapłana, pokropienie wodą święconą, błogosławieństwo krzyzem oraz nałożenie pierścionka przez męzczyznę. Te zaprowadzone w VIII w. formy były zachowywane równiez wastępnym okresie. Ibn at-Taijlb zalicza do lstotnych składników umowy małzeńskiej pośrednictwo kapłana, wiernych, modlitwę, krzyż, plerśclonek 1 relikwie. Katolikos Tymoteusz II ${ }^{18}$ zaś opisywał zamarcie małzeństwa następujaco: kapłan błogosławi kielich z mieszanym winem, które nowozeńcy p1ja; wymagane sa ponadto: krzyz, pierścionek 1 hnānā.

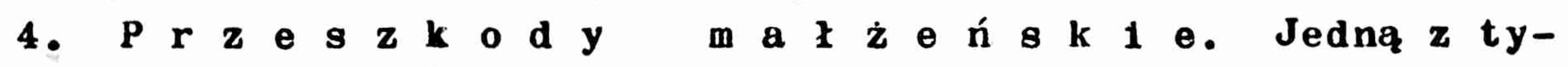
powych przeszkód małzeńskich było pokrewieństwo 1 powinowactwo. Tak np. Mār Abā-19 zabronił krewnym wchodzić w zwiazki małzeńskie 1 wyszczególnił następujące przypadk1 unieważniające małzeństwo: z zoną swego ojca, z bratem ojca, z clotką, z siostrą, z córka szwagra, z potomstwem córki. Wyraźał ubolewanie, ze są ludzie którzy waza się zblizyć do macochy, ciotki, siostry, synowej, szwaglerki jak Źydzi lub niewierni, ale tacy winni byc wykleci 20 . Podstawa jego rozmazań o zapobieganiu małzeństwu krewnych ${ }^{21}$ były teksty $z$ Księgi Kapłańskiej/18,6-19;20,10-21/. Zydowski zwyczaj lewiratu został odrzucony przez prawodawstwo nestoriańskie $22 / I b n$ at - Tajjib, Išo' bokt/. Czy zaś istniał zakaz małżeństwa kobiety z dwoma braćmi /jeden po drugim/ lub męzczyzny z dwiema siostrami, nie mozna wyraźñe stwierdzi ${ }^{23}$. Zdantem Išo' bar Nuna zakaz małzeństma byl rozciagnięty nawet na rodzeństwo panny ulodej, a niekiedy 1 narzeczonego. Zakaz wielożeństwa jest bezsprzecznie stwierdzony równiez u Innych autoróm/kan. 13 Išol jahba/.

Jeśli chodzi o przeszkodę różności religile, to chrześcijanin mógł wprawdzle poślublé niechrześcijankę nadziei jej nawrócenia, ale nie mogła niewlasta chrześcijańska poślubić wyznawcy

18 H.Kaufrold, dz.cyt., 79.

19 0.Braun, dz,cyt., 94.

20 Tanze 143.

21 W.Selb, dz,cyt., 152.

22 H.Kaurhold, dz.cyt., 66.

23 Tainze 67.

24 Tanże 68. 
Innej religil z powodu niebezpieczeństwa utraty wiary/kan. 14 katolikosa Jerzego $\mathrm{I} /$. Zdaniem Ibn at-Taijiba zakaz małzeństwa z niechrześcijanami został rozciagnięty również na duchownych.

T razie niezdatności męźczyzny do małzeństwa ${ }^{25}$, kobieta, która go opuściła mogła sie wydać za drugiego męzczyznę. Nie rozróżniano przy tym, czy ta niezdatnośc nastąpiła przed czy po umowie małzeńskiej, ale przed wprowadzeniem do domu. Nie podtrzymano jednak tezy Išoc bar Nuna26, ze opętany nie moze się żenić.

5. R O $z$ ó d. Nie ma jednolitości poglądów u autorów nestoriańskich co do liczby przyczyn rozejścia się małzonków 27. Zdaniem Išol bar Nuna są trzy, a według Tymoteusza cztery przyczyny rozmodóm: zachowanie czystości, cudzołóstwo, magia 1 morderstwo. Gabriel z Basry natomiast wymienia następujace powody do rozwodu: rabunek, przyjecie prostytutki do domu, sodomia, zagrozenie kobiecie zelaznym przedmiocem.

Cudzołóstwo było róznie rozumiane przez autorów nestoriańskich ${ }^{28}$. Oprócz cielesnego obcowania z osobaz już komuś poślubiona uznawano też cudzołóstro duchowe, takie jak magia 1 kult demonów. Takze ostateczne odejście było uważane za cudzołóstwo 1 po kanonicznym zbadaniu pozwalano opuszczonemu współmałżonkowi na powtórne małżeństwo, gdy juz nie było nadzlei na ponowne ozywienie wspólnoty małżéskiej. W przypadku gdy cudzołóstwo lub równorzędne uchybienia przecíw małzeństwu były podstawa do rozwodu, tylko niewinnemu wspómałzonkowi pozwalano na powtórne małżéstwo.

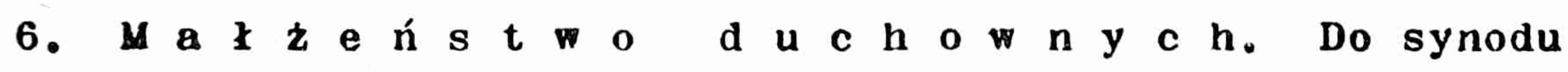
Akakis /468 r./, na którym nastz̨piło przyjęcie nauki nestoriańskiej, kapłan1 1 wyżze duchowieństwo żli według dotychczasowych reguł kościelno-cesarskich zachowując bezzeństwo, jeżell przed święceniami nie zawarli zwick ku małzeńskiegro lub zamarcie małżenstwa było zastrzeżone przy święcentach ${ }^{29}$. Hewolucyjne postanowienie wprowadził dopiero schizmatyoki synod Bar Saumy /484 r./ w Bet Lāpat, zno-

25 w.Selb, dz.cyt.,213。

26 H.Kaurhold, dz,cyt, 70 .

27 Tamże 85.

28 W.Selb, dz.cyt., 210 .

29 Tauże 140. 
sząc zakaz zawierania małzeństwa przez kleryków gotowych przyjąć kapłaństwo. Następne synody przejęly inicjatywe 1 ustanowiły nowe reguły. Kanon 3 synodu Akakjis postanowit, ze kandydaci gotow do kapłaństwa mogli zawierać ważne małzeństwo, a biskup1 przestali być zmuszan1 do bezżennośc1. Tenże kanon wyjaśniał, ze zawarcie małzeństwa winno być dozwolone klerykow1, zarówno przed jak 1 po św1ęconiach oraz jasno przestrzegał, by duchowny nie brał równocześnie dwu kobiet, względnie nie trzymał konkubiny oprócz żony. 7. 'A b d $\bar{i}$ s $\bar{o}^{(}$B a r
B a $\mathbf{h} \mathbf{r} \overline{\mathbf{i}} \mathbf{z}$.
Dz 1 eło 'A Bahrīzo /X/XI w./ pod tytułem "Prawo małżeńskie 1 ziemskie" nalezy do prawniczej literatury kościoła nestoriańskiego za kalifatu Abbasydów. Pierwsza jego część jest interpretacja do Kpł 18,6.7-17 31 . Główny problem, jaki sie w nim najpierw pojawia, to umowa małzeńska 32 , oznaczająca kontrakt małzeński, po którya nastepuje przepromadzonio do domu.

Autor zajmuje się następnie czasokresem, jaki jest potrzebny w wyadku rozejścia sie od umowy malzeńskiej az do powírnego mazzeństwa ${ }^{33}$, zaznaczając, ze wymagany jest okres trzech lat przypadku odejscia męzczyzny; wówczas to kobieta jest wolna 1 moż wyjść za mąż. Išoc bar Nun przyjmuje natomiast okres aż czterech lat.

Jak długo powinien trwać okres oczekiwania dla przeprowadzonej do domu kobiety w przypadku nieobecności męza? Prawo syryjsko-rzymskie przewidywało okres 7 lat. Powtórne małzoństwo nlewinnej osoby jest dozwolone, winny zaś partner nie moze zawrzeć nowego małzeństwa, gdyż już został wyłączony ze społeczności wiernych. Równieź niewiara jednej strony daje podstawę do rozwodu. Jaki wpływ ma choroba na trwałość zwiazzku małzeńskiego? Po fakcie przeprowadzenia do domu choroba nie daje zadnych powodów do rozwiqzania małzeństwa.

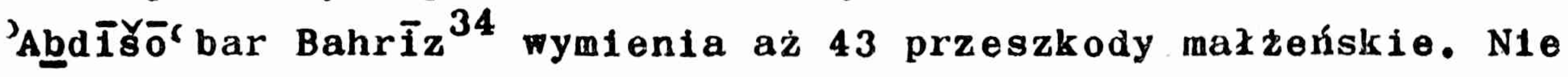
zezwala m.in. na małzeństwo z rodzicami 1 dziadkami, na małzeństwo dziecí maźzonków $z$ jego rodzicami, na małżéstwo z wujostwem ze strony ojca, a także z rodzeństwem oraz dwiema kobietami równocześnie.

30 W.Selb, 'Abdišór bar Bahrīz Ordnung der Ehe und der Erbschapten sowie Entscheidung von Rechtspllien, Wien 1970.

31 Tamże 131.

32 Tamże 133.

33 Tamże 134.

34 Tamże 31-37. 
Jak długo musi wytrwać kobieta związana umowaz małzeńskz? ${ }^{35}$ Bez wsparcia partnera umowy - trzy lata, z jego zaś zapomoga - siedem lat. Jak długo musi kobleta czekać, jeśli mazz ją opuścił? Gdy jest wspomagana ze strony męza dziesięc lat, w przeciwnym wypadku sledem lat.

Widzimy, ze nestoriańskie prawo małzeńskie nie jest jednolite. Podlegało procesowi rozwoju oraz wpływom kościoła greckiego 1 sąsiednich kościołow or lentalnych. Stało jednak na strazy dobra człowieka Pormujac tyle róznych przeszkód małzeńskich. Jego cechą charakterystyczna jest małzeństwo dwuetapowe oraz ustalone sposoby otrzymanta rozmodu. Posiada równiez piękny rys świętości, kiedy to choroba małzonka nie dawała powodu do rozwodu, lecz była okazja do okazanta wiernośc1 drugiej stronte.

Ks. Jerzy Poźntak CM - Kraków

\section{LE MARIAGE DANS L'ENSEIGNBMENT ET LA LEGISLATION DES NESTORIENS /Hésumé/}

Le source pour connaitre la conception du mariage chez les Nestoriens 11 y a des documents des synodes et compendia. Le mariage a été fait parail comme chez les Juifs en deux étapes: par le contrat de mariage et le déménagement à la maison. Le contrat de marlage a été falt par les parents mais ensuite 11 y avait le déménagement à la ma1son, si le mariage avait été accompl1. Les formes de falre le marlage ont développé dans le perlode tardive de la législation nestorienne. Timothé et Išol Bar Nun considerent comme une suffisante forme du contrat de marlage la présence du prêtre, la bénédiction de la crolx, l'alliance donnéepar l'homme. Selon Timothé existent quatre raisons du divorce des maries: l'observation de la chasteté, l'adultére, la magle, la crime. Par 1'adiltere spirituel on comprends la magie et le culte des demons. 'Abd1šo'Bar Bahriz Pait une description des suivants problemes: le contrit de marlage, secondalre le mariage, les obstacles de mariage. D'apres lui le mariage secondaire est permit en cas de la personne Innocente. La léglslation de marlage des Nestoriens n'est pas uniforme et a été subordonnéé les influences de l'église grecque et des églises orientales. 